\title{
The Insignificant Role of National Culture in Global Lean Programmes
}

\author{
Torbjørn H. Netland ${ }^{1,2}$, Miguel Mediavilla ${ }^{3}$, and Ander Errasti ${ }^{4}$ \\ ${ }^{1}$ NTNU, Trondheim, Norway \\ ${ }^{2}$ Georgetown University, Washington DC, USA \\ ${ }^{3}$ BSH GmbH, Munich, Germany \\ ${ }^{4}$ University of Navarra, San Sebastián, Spain \\ torbjorn.netlandaiot.ntnu.no
}

\begin{abstract}
Large corporations are increasingly implementing lasting corporate improvement programmes based on lean thinking in their global production networks. The aim is to improve operational efficiency by sharing best operational practices and foster continuous improvement among all subsidiaries. However, it remains an open question why implementation success differs substantially across cultures and sister plants for most companies. We review the existing literature on improvement programmes and culture, and compare the current state of the art with unique quantitative data from 80 factories belonging to two global manufacturing companies. We surprisingly find no explanatory power in national culture (measured with Hofstede's model) and propose that other factors such as the organisational culture and the strategic role of the plant matters far more.
\end{abstract}

Keywords: Company-specific Production Systems, National Culture, Organisational Culture, Global Production, Lean.

\section{Introduction}

In order to improve the efficiency and effectiveness of operations worldwide, companies have increasingly embarked on corporate-wide improvement programmes. Inspired by the great success of Toyota's global deployment of the Toyota Production System (TPS), companies have developed company-specific variants of the TPS [1]. However, success does not come free of challenges. A particular challenge for multinational companies is to implement the same type of thinking with its methods and tools in a diverse world of different needs, cultures and beliefs.

According to Hofstede and Hofstede [2] national culture is the "collective programming of the mind" that make one nation distinctive different from another. Such national cultures are extremely hard to change because they are institutionalised in the societies. There is much research that investigate the impact of national culture on different improvement programmes [e.g. 3, 4, 5], but our literature review shows that the current research is largely inconclusive in which specific cultures are favourable for the programme implementation. We also find that there is abundance of research that 
use perception-based surveys to empirically investigate the link between Hofstede's five cultural dimensions and process improvement, but real-life case studies that make use of factual performance data are rare or absent in the current literature.

We contribute to literature and practice by-once again-investigating the role of national culture in improvement programme efforts. First we want to investigate if the usual assumption that Hofstede's 5D model can explain performance differences is waterproof. We therefore ask: Do Hofstede's cultural dimensions explain differences in XPS implementation? (RQ1). We investigate these two questions empirically through real-life case studies, where we make use of rare and original data to test and explore the findings in previous studies.

We acknowledge that other factors can either triumph disadvantages in national cultures or impede favourable national cultures, and we therefore include a second research question: What other factors are likely to explain differences in XPS implementation? (RQ2). This second research question is subject to discussion in our post-hoc analysis.

\section{Literature Review}

An XPS follows the belief that there are "best practices" that are applicable in all nations [6]. But because cultures differ, practices are likely to differ across cultures. Therefore, many authors argue that a contingency approach is needed, where a good fit between the context and adapted practices is needed for good performance. Thus, the local culture in which the subsidiary operates influences the receptiveness of the XPS, and hence its implementation success. It is suggested that some cultures have more favourable traits for improvement programmes than others [7]. The question arises: Which cultures are better for the implementation of an XPS?

This question has been abundantly investigated in operations management research. Popular approaches in this research is to operationalise national culture based on Hofstede's [8, 9] well-defined and much used types of culture attributes $[3,5,7,10,11]$, or the extension known as the GLOBE-framework [4, 12, 13]. In his seminal study of 116.000 employees in IBM in 50 countries from 1967-1973, Hofstede [9] suggested four cultural dimensions: High versus low power distance, individualism versus collectivism, high versus low uncertainty avoidance, and masculinity versus femininity. Later he added long-term versus short-term orientation as a fifth and final dimension. These five culture types are summarised in Table 1.

Table 1. Hofstede's 5 dimensions for national culture

\begin{tabular}{ll}
\hline Dimension & Description (Source: http://geert-hofstede.com) \\
\hline $\begin{array}{l}\text { Power distance } \\
\text { (PDI) }\end{array}$ & $\begin{array}{l}\text { The extent to which the less powerful members of institutions and organisations } \\
\text { within a country accept that power is distributed unequally. }\end{array}$ \\
\hline $\begin{array}{l}\text { Individualism } \\
\text { (IDI) }\end{array}$ & $\begin{array}{l}\text { In Individualist societies people look after themselves while in Collectivist-societies } \\
\text { people belong to "in-groups" that care for them. }\end{array}$ \\
\hline Masculinity & $\begin{array}{l}\text { The fundamental issue is what motivates people; wanting to be the best (masculine } \\
\text { (MAS) }\end{array}$ \\
society) or liking what you do (feminine society). \\
$\begin{array}{l}\text { Uncertainty } \\
\text { avoidance (UAI) }\end{array}$ & $\begin{array}{l}\text { The extent to which the members of a culture have created beliefs and institutions } \\
\text { that try to avoid risks and uncertainty. }\end{array}$ \\
\hline $\begin{array}{l}\text { Long-term } \\
\text { orientation (LTO) }\end{array}$ & $\begin{array}{l}\text { The extent to which a society shows a pragmatic future-oriented perspective rather } \\
\text { than a conventional historical short-term point of view. }\end{array}$ \\
\hline
\end{tabular}


We reviewed the literature that investigates the effect of cultural dimensions on improvement programmes using Hofstede's 5D model or the same dimensions collected from the GLOBE framework. The review is summarised in Table 2.

Table 2. Review of the effect of cultural dimensions on improvement programmes

\begin{tabular}{|c|c|c|c|c|c|c|c|c|c|c|}
\hline Paper & Data* & Programme & Culture & 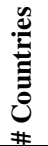 & $\frac{\stackrel{n}{\Xi}}{\underline{E}}$ & $\overline{\mathrm{a}}$ & $\overline{\mathbf{\theta}}$ & $\sum_{\Sigma}^{\infty}$ & 岕 & ב \\
\hline $\begin{array}{l}\text { Wiengarten et } \\
\text { al. }[10]\end{array}$ & $\begin{array}{l}\text { GMRG } \\
\text { survey }\end{array}$ & $\begin{array}{l}\text { Quality } \\
\text { practices }\end{array}$ & Hofstede 4D & 15 & 960 & 0 & - & - & - & $n i$ \\
\hline $\begin{array}{l}\text { Cagliano et al. } \\
\text { [11] }\end{array}$ & $\begin{array}{l}\text { IMSS } \\
\text { survey }\end{array}$ & Work org & Hofstede 4D & 21 & 660 & - & $+/-$ & - & - & $n i$ \\
\hline $\begin{array}{ll}\text { Flynn } & \& \\
\text { Saladin [10] } & \\
\end{array}$ & $\begin{array}{l}\text { WCM } \\
\text { survey }\end{array}$ & $\begin{array}{l}\text { Baldrige } \\
\text { Quality Award }\end{array}$ & Hofstede 4D & 5 & 164 & + & - & + & + & $n i$ \\
\hline Lagrosen [3] & $\begin{array}{l}\text { Survey } \\
1 \mathrm{MNC}\end{array}$ & TQM & Hofstede 4D & 30 & 47 & $n s$ & $+/-$ & ns & - & $n i$ \\
\hline $\begin{array}{lll}\text { Power } & \text { et } & \text { al. } \\
{[14]} & & \\
\end{array}$ & $\begin{array}{l}\text { GMRG } \\
\text { survey }\end{array}$ & $\begin{array}{l}\text { Quality, lean, } \\
\text { TQM etc. }\end{array}$ & $\begin{array}{l}\text { Individualist } \\
\text { vs collectiv. }\end{array}$ & 9 & 639 & $n i$ & - & $n i$ & $n i$ & $n i$ \\
\hline $\begin{array}{l}\text { Galperin \& } \\
\text { Lituchy [15] }\end{array}$ & $\begin{array}{l}\text { Case } \\
\text { study }\end{array}$ & TQM & $\begin{array}{l}\text { Individualist } \\
\text { vs collectivist }\end{array}$ & 2 & 10 & $n i$ & - & $n i$ & $n i$ & $n i$ \\
\hline $\begin{array}{l}\text { Kull \& Wacker } \\
\text { [6] }\end{array}$ & $\begin{array}{l}\text { GMRG } \\
\text { survey }\end{array}$ & $\begin{array}{l}\text { Quality } \\
\text { practices }\end{array}$ & GLOBE & 3 & 222 & 0 & $n i / 0$ & $n i$ & + & 0 \\
\hline Naor et al. [16] & $\begin{array}{l}\text { HPM } \\
\text { survey }\end{array}$ & $\begin{array}{l}\text { Cost/quality/deli } \\
\text { very/flexibility }\end{array}$ & GLOBE & 6 & 189 & - & - & $n i$ & + & + \\
\hline $\begin{array}{l}\text { Vecchi \& } \\
\text { Brennan [15] }\end{array}$ & $\begin{array}{l}\text { IMSS } \\
\text { survey }\end{array}$ & $\begin{array}{l}\text { Quality } \\
\text { practices }\end{array}$ & GLOBE & 24 & 711 & + & $+/-$ & - & - & - \\
\hline & & & & & $\Sigma$ & $?$ & - & $?$ & $?$ & 0 \\
\hline
\end{tabular}

* GMRG = Global Manufacturing Research Group | IMSS = International Manufacturing Strategy Survey $\mid$ WCM = World Class Manufacturing Project $\mid H P M=$ High Performance Manufacturing Project.

+ / - / 0: The impact of the cultural dimension on implementation performance: $n i=$ Not investigated I ns= No significance.

There is mixed evidence for four out of the five cultural dimensions in the literature. The research to date suggests that the only dimension that for sure increases implementation of quality practices is low individualism, also referred to as a collectivist culture. The studies that use the GLOBE framework instead of Hofstede's model find that this picture should be nuanced: First, Kull and Wacker [4] found that institutional collectivism has no specific affect on implementation and argue the same for in-group collectivism. Second, Vecchi and Brennan [12] found that in-group collectivism do positively affect implementation while the opposite effect is found for institutional collectivism. Third, Naor et al. [13] find that both types of collectivism weakly but positively influence performance. Thus, the only thing we can say for sure across these studies is that in-group collectivism seems to positively influence improvement programme implementation. Several authors find that the coexistence of several cultural dimensions however substantially mediates the effect of collectivism. These studies find that different cultures have different strengths and weakness when it comes to implementing global lean programmes and suggest that there is not one unique culture type that fits perfect [16]. The conclusion from our review must be that there is great confusion in literature on if and how the different cultural dimensions affect the implementation of improvement programmes with the notable exception of in-group individualism. 


\section{$3 \quad$ Methodology}

To investigate the role of national culture on XPS implementation we chose an explorative multiple-case approach [17]. Data and experiences from 80 plants belonging to two global players in different industries are utilised. In particular we build on quantitative assessment data that are collected throughout the two case companies in a rigid and standardised way. In our post-hoc analysis we also take advantage of our visits to most of the plants in the sample.

\subsection{Case Companies}

Company $\mathrm{A}$ is a worldwide operating appliances corporation and is headquartered in Germany. The company has over 40 factories operating in Europe, the USA, Latin America and Asia, and employing approx. 40,000 people. Company A's XPS has been implemented in 34 plants in 7 countries since the beginning of 2007. The assessment data for company A have been collected through on-site audits based on a standardised questionnaire.

Company B is a major player in the transportation industry and is headquartered in Sweden. It has more than 60 plants all over the world. Company B's XPS has been implemented in more than 50 plants since 2007. The maturity assessment data for company $\mathrm{B}$ have also been collected through on-site reviews based on a standardised questionnaire.

\subsection{Operationalisation of the Variables}

Case A and B have provided the authors with original XPS assessment data. This data is based on structured and thorough assessments of the implementation of XPS in the companies. The assessments are carried out by trained assessors that follow standard assessment schemes over several days. For each plant in the sample, a score summarises how much the plant has implemented lean methods and tools. Even if the content is basically similar and largely resembles that of lean thinking, the XPS scoring process is different between the companies. We therefore normalised the data across the cases using z-scores. The sample covers 23 countries. Figure 1 summarises the XPS implementation z-scores for the countries included in our sample.

We controlled for differences between the MNCs by analysing the countries that are part of both samples ( 9 plants in US, 9 in Germany, 6 in France, 8 in China, and 4 in Poland). We found a very good fit between the datasets for these countries, which justifies discussing the two datasets as one. As a consequence we merged the results for the same countries from both MNCs into one z-score using the simple mean of the two z-scores.

To operationalise the national culture, we use Hofstede's 5D indexes [e.g. 2, 10]. This index comes with pre-defined and tested measures for most countries in the world. These scores are publicly available through the web-page http://geerthofstede.com. 


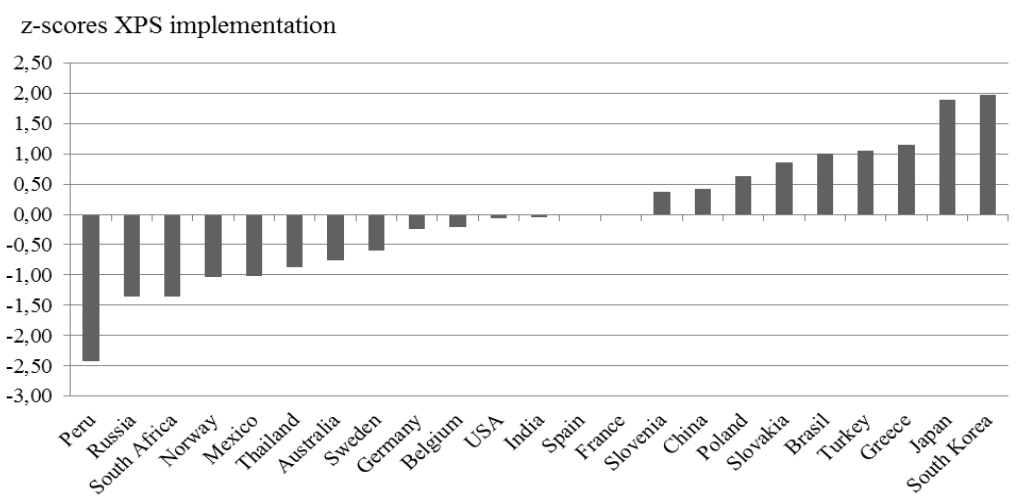

Fig. 1. Z-scores for XPS implementation across the 23 countries in the sample

\section{Discussion}

\subsection{Do Hofstede's Cultural Dimensions Explain Differences in XPS Score?}

The correlation analysis given in Table 3 finds no significant correlation between Hofstede's five cultural dimensions and XPS implementation. The only dimension that is significant at a $10 \%$ level is long-term orientation which positively influences implementation.

Table 3. Correlations between z-scores and Hofstede's 5D model

\begin{tabular}{l|ccccc}
\hline Indep. variable* & PDI & IDI & MAS & UAI & LTO \\
\hline Pearson's r & .131 & -.155 & .313 & .251 & .463 \\
\hline Significance & .552 & .480 & .145 & .248 & .071 \\
\hline $\mathrm{N}$ & 23 & 23 & 23 & 23 & 16 \\
\hline
\end{tabular}

*Correlations with dependent variable XPS implementation z-scores.

In support of the finding that national culture seems not to explain too much, we also find quite large difference between plants in some of the countries. This is particular true for countries such as Sweden, France and Germany where we both find good and less good performing plants.

It seems like Hofstede's 5D model has limited explanatory power in the implementation of XPSs in our two case companies. We do not even find significant support for the only dimension that previous literature agrees matters $[7,10,13,14]$ : low degree of individualism, i.e. collectivism. (The only sign of support, even if not significant, is that IDI is as expected the only factor that loads negatively on XPS implementation). If this is the case in our two MNCs, it is probably also the case in other MNCs. We cannot conclude that the national cultures have no effect, but our first proposition will be: (P1) Whatever the effect of Hofstede's cultural dimensions on XPS implementation are, there are other factors in the plants that by far triumph these cultural dimensions. 


\subsection{What Other Factors Can Explain Differences in XPS Implementation?}

We now proceed with our post-hoc analysis for some alternative explanations for the XPS implementation in our cases (c.f. Figure 1).

A first possible explanation for differences in performance is naturally organisational culture. There are numerous studies that establish that the successful transfer of management and operational practices is less dependent on the national culture than on the organisational culture $[13,18]$. It has long been established that it is possible to successfully implement lean production in cultures very different from the Japanese [18, 19]. Deal and Kennedy [20] define organisational culture as "the way things get done around here". As demonstrated with this definition, organisational culture is not clear-cut. In general, it lacks good operationalisation in the literature and is so multi-faceted that we still do not know exactly how to build organisational cultures that sustain high XPS performance. Our field studies in the case companies clearly indicate that organisational culture is of major importance, but our quantitative data do not allow any analysis of this sort. We can only keep this as a proposition for further research: (P2) A plant's organisational culture can triumph any effects of national cultures in the implementation of an XPS.

A second possible explanation is the strategic role of the plant. Ferdows [21] suggested that plants can have different roles based on their strategic importance. While the concept of factory roles have been subject to testing and refining [22, 23], only few studies explicitly investigate the link between factory role and improvement programmes [24]. Mediavilla et al. [24] found some evidence that the lower the plant role, the more actively the plants try to implement the improvement programme with the purpose of increasing its role. Consequently, this would also mean that the higher the role of the plant the more ambivalent the plant would be to implement the programme. The reasoning for this will be that plants that are specifically put up for the purpose of offshored production compete solely on the basis of their operational competitiveness. We find partial support for this proposition in our data, with lowrole plants that perform well with XPS implementation in China, Poland, Slovakia, Brazil, Turkey and Greece. Also the fact that high-role plants in Sweden, Germany, France, USA and Belgium seem to cluster around and above the average support this. However, it does not explain that the high-role plants in South Korea and Japan perform best of all, and that low-role plants in Peru, Russia, South Africa, Mexico and Thailand perform well below average. Possible explanations for the latter might be proprietary markets and a high degree of plant autonomy in these countries, or simpler explanations like the learning curve effect. As globalisation increases also in these countries we might see a change in the future. With the need for more research we conclude with our third proposition: (P3): The lower the role of the plant in the global network, the higher the external and internal pressure for XPS implementation will be.

\section{Conclusions}

In the literature review we found mixed evidence on which cultural dimensions impact XPS implementation, and our analysis suggest this has a good reason; the 
impact of national culture on global lean programmes is insignificant. Cultural dimensions, such as the ones summarised by Hofstede, explain little of the successful implementation of global lean programmes. Instead we should search for other explanatory factors that far outweigh the impact of national culture. The literature to date has suggested that organisational culture is one such important factor; we suggest the plant role is another factor that deserves more attention in future research.

\subsection{Implications for Researchers}

If we are right, researchers should reduce all the work that goes into analysing the link between global manufacturing surveys and cultural dimensions based on Hofstede. Even if that type of research is relatively easy to conduct and get published, its contribution to practice is more confusing than helpful. Correspondingly more research is needed to explore the three other propositions we set forward. So far, most published research seems to fall into one type of research designs: Large multinational surveys based on perceptual answers from a single or few respondents in each plant. We call for more research that utilise real plant performance data like we do here. We also encourage collaborative studies with between practitioners and researchers. We think that can help resolve the gridlock picture of cultural impact on global lean programmes. Longitudinal case studies are in consequence a preferable research strategy.

\subsection{Implications for Managers}

With the realisation that managers cannot change the national culture but can impact the other factors that we suggest impact XPS implementation even more, our findings are in fact good news for global managers. If our second proposition is right, managers can delimit negative traits and enhance positive traits in the national culture if such exist, by building supportive organisational cultures for different contexts. There is available a vast literature on critical success factors for improvement programmes. If our third proposition is right, global managers would know what XPS performance to expect from each plant based on their role. Thus, resources can more economically be employed where needed in the network.

\subsection{Limitations}

Our data have several limitations which is why we conclude with propositions and not assertions. First, the numbers of plants in each of the countries we investigate vary from 1 to 10; a cursory look at our results show that the more plants you include from one country the closer to the mean that country ends. Therefore caution should be taken when analysing the end points in our country scale. This, however, lends support to our first proposition that national culture is insignificant. Second, the assessment data-even if rigid and robust-does only tell how much of the XPS a plant has implemented, not how well the plant is performing. In the real world, companies ultimately compete with performance and not implementation of lean programmes, even if a positive correlation between them is expected. Third, it should 
also be noted that other classifications for national culture exist, and might provide better explanations for XPS implementation than Hofstede and GLOBE that we base our analysis on her. We leave the task of addressing our limitations to future research.

\section{References}

1. Netland, T.H.: Exploring the phenomenon of company-specific Production Systems: Onebest-way or own-best-way? International Journal of Production Research (2012), doi:10.1080/00207543.2012.676686.

2. Hofstede, G., Hofstede, G.J.: Cultures and organizations: software of the mind, vol. XII, p. 434s. McGraw-Hill, New York (2005)

3. Lagrosen, S.: Exploring the impact of culture on quality management. International Journal of Quality \& Reliability Management 20(4), 473-487 (2003)

4. Kull, T.J., Wacker, J.G.: Quality management effectiveness in Asia: The influence of culture. Journal of Operations Management 28(3), 223-239 (2010)

5. Newman, K.L., Nollen, S.D.: Culture and Congruence: The Fit between Management Practices and National Culture. Journal of International Business Studies 27(4), 753-779 (1996)

6. Laugen, B.T., et al.: Best manufacturing practices: What do the best-performing companies do? International Journal of Operations \& Production Management 25(2), 131 (2005)

7. Flynn, B.B., Saladin, B.: Relevance of Baldrige constructs in an international context: A study of national culture. Journal of Operations Management 24(5), 583-603 (2006)

8. Hofstede, G.: Think Locally, Act Globally: Cultural Constraints in Personnel Management. Management International Review 38, 7 (1998)

9. Hofstede, G.: Culture's consequences: International differences in work-related values. Sage, Beverly Hills (1980)

10. Wiengarten, F., et al.: Exploring the impact of national culture on investments in manufacturing practices and performance. International Journal of Operations \& Production Management 31(5), 554-578 (2011)

11. Cagliano, R., et al.: The impact of country culture on the adoption of new forms of work organization. International Journal of Operations \& Production Management 31(3), 297$323(2011)$

12. Vecchi, A., Brennan, L.: Quality management: a cross-cultural perspective based on the GLOBE framework. International Journal of Operations \& Production Management 31(5), 527-553 (2011)

13. Naor, M., Linderman, K., Schroeder, R.: The globalization of operations in Eastern and Western countries: Unpacking the relationship between national and organizational culture and its impact on manufacturing performance. Journal of Operations Management 28(3), 194-205 (2010)

14. Power, D., Schoenherr, T., Samson, D.: The cultural characteristic of individualism/collectivism: A comparative study of implications for investment in operations between emerging Asian and industrialized Western countries. Journal of Operations Management 28(3), 206-222 (2010)

15. Galperin, B.L., Lituchy, T.R.: The implementation of total quality management in Canada and Mexico: a case study. International Business Review 8(3), 323-349 (1999)

16. $\mathrm{Zu}, \mathrm{X}$., Robbins, T.L., Fredendall, L.D.: Mapping the critical links between organizational culture and TQM/Six Sigma practices. International Journal of Production Economics 123(1), 86-106 (2010) 
17. Yin, R.K.: Case study research: design and methods, vol. XVI, p. 181s. Sage, Thousand Oaks (2003)

18. Krafcik, J.F.: Triumph of The Lean Production System. Sloan Management Review 30(1), 41-51 (1988)

19. Womack, J.P., Jones, D.T.: Lean thinking: banish waste and create wealth in your corporation, p. 396s. Free Press, New York (1996)

20. Deal, T.E., Kennedy, A.A.: Corporate cultures: the rites and rituals of corporate life, vol. VII, p. 232s. Addison-Wesley, Reading (1982)

21. Ferdows, K.: Making the most of foreign factories. Harvard Business Review 75(2), 73 (1997)

22. Maritan, C.A., Brush, T.H., Karnani, A.G.: Plant roles and decision autonomy in multinational plant networks. Journal of Operations Management 22(5), 489-503 (2004)

23. Vereecke, A., Dierdonck, R.V., Meyer, A.D.: A Typology of Plants in Global Manufacturing Networks. Management Science 52(11), 1737-1750 (2006)

24. Mediavilla, M., Errasti, A., Domingo, R.: Framework for evaluating and upgrading the strategic plant role. Case study within a global operations network. DYNA Engineering and Industry 86(4), 405-451 (2011) 